\begin{tabular}{|c|l|}
\hline Title & Tensile properties of Co-based oxide dispersion strengthened superalloys \\
\hline Author(s) & Yu, Hao; Ukai, Shigeharu; Oono, Naoko \\
\hline Citation & Journal of A lloys and Compounds, 714, 715-724 \\
\hline https://doi.org/L0.1016/.jallcom.2017.04.276
\end{tabular}

Instructions for use 


\title{
Tensile properties of Co-based oxide dispersion strengthened superalloys
}

\author{
Hao $\mathrm{Yu}^{{ }^{*}}$, Shigeharu $\mathrm{Ukai}^{2}$, Naoko Oono ${ }^{2}$ \\ ${ }^{1}$ Graduate school of Engineering, Hokkaido University, N13W8 Kita-ku, Sapporo \\ 060-8268, Japan \\ ${ }^{2}$ Faculty of Engineering, Hokkaido University, N13W8 Kita-ku, Sapporo 060-8268, \\ Japan \\ E-mail of the corresponding author: qqyu1111@163.com (Hao Yu) \\ Tel.: +81-080-6077-1807 Fax: +81-11-706-6356
}

\begin{abstract}
Tensile properties of a novel Co-20Cr-5Al-2.4Hf- $1.5 \mathrm{Y}_{2} \mathrm{O}_{3}$ (wt\%) oxide dispersion strengthened (ODS) superalloy were studied through a comparing investigation with Co-20Cr-5Al (wt\%) alloy. Both the Co-based alloys (with and without oxide particles) were fabricated by mechanical alloying (MA), spark plasma sintering (SPS), hot rolling and the final annealing at $1200{ }^{\circ} \mathrm{C}$. Due to the ultrafine grains of $500 \mathrm{~nm}$ in the ODS superalloy and $1.2 \mu \mathrm{m}$ in the ODS free alloy, the metastable fcc structure predominates at room temperature. Tensile testing was conducted at room temperature and $1000{ }^{\circ} \mathrm{C}$. Strain-induced twinning deformation was evidenced by transmission electron microscopy and was found to significantly enhance the ultimate tensile strength (UTS) of the two alloys at room temperature. The Co-based ODS superalloy exhibits a superior tensile strength of $2.85 \mathrm{GPa}$ at room temperature, which is associated with the distribution of twins and fine Y-Hf oxides. At $1000{ }^{\circ} \mathrm{C}$, since the ultrafine grain size in the ODS superalloys, an easy grain boundary deformation occurred and resulted in a significant reduction in the UTS value.
\end{abstract}

\section{Keywords}

Co-based superalloys; Oxide dispersion strengthening; strain-induced twin deformation 


\section{Introduction}

Although cobalt-based alloys show less strength than nickel-based alloys at higher temperatures, they are still irreplaceable due to their prominent hot corrosion resistance, which makes possible to apply for widely used guide vanes of aviation jet engines and the stationary blades of industrial gas turbines [1, 2]. The oxide dispersion strengthening (ODS) is expected to be an advanced approach to increase service temperature of superalloys [3-5], since an extremely high thermodynamic stability of dispersed oxide particles and an adjustable composition of matrix, which could guarantee the availability of a stable secondary strengthening phase and a superior oxidation resistance with the formation of $\mathrm{Al}_{2} \mathrm{O}_{3}$ oxide scale at elevated temperature. Considering the coarsening or dissolving of carbides in conventional Co-based alloys above $800{ }^{\circ} \mathrm{C}$ [6], and the limited oxidation resistance of lately developed $\gamma^{\prime}$-strengthened Co-based alloys with a narrow composition design [7, 8], we have focused on the developing of Co-based ODS superalloys, which are expected to be applicable at higher temperature of $1000{ }^{\circ} \mathrm{C}$. A significant improvement of tensile strength at $1000{ }^{\circ} \mathrm{C}$ on Co-3Al-1.5 $\mathrm{Y}_{2} \mathrm{O}_{3}-1.2 \mathrm{Hf}$ (wt\%) ODS superalloy was obtained by Takezawa et al. [9] through comparison testing with the non-ODS Co-based alloy with the same basic composition. However, there are few reports about the tensile strength of Co-based ODS superalloys at low temperature.

In general, polycrystalline metals could be gained via the process of MA [10-12] and the polycrystalline cobalt usually consists of a $\gamma$ face-centered cubic (fcc) phase and a $\varepsilon$ hexagonal close-packed (hcp) phase at room temperature [13]. References [14, 15] have claimed that the $\gamma$-cobalt phase is metastable at room temperature and will experience a strain-induced $\gamma-\varepsilon$ martensitic transformation by deformation for the mechanical alloyed (MAd) cobalt. It's also reported that the strain-induced $\gamma-\varepsilon$ transformation occurs simultaneously with twinning deformation in ultrafine and nanocrystalline cobalt as strain increased in surface mechanical attrition treatment [16, 17]. Both the $\varepsilon$-martensite and twin boundaries act as strong barriers for blocking dislocation slipping $[16,18]$. Therefore, it's significant to make out the deformation mechanism of the Co-based ODS superalloys at low temperature through researching 
the tensile properties at room temperature. Besides, the deformation at elevated temperature is another key point for the development of the Co-based ODS high-temperature superalloys.

In the present work, a novel Co-20Cr-5Al-2.4Hf-1.5 $\mathrm{Y}_{2} \mathrm{O}_{3}$ (wt\%) ODS superalloy was designed and fabricated. Tensile properties of the manufactured specimens were investigated at room temperature and $1000{ }^{\circ} \mathrm{C}$, focusing on the characterization of uniquely deformed structure and oxide particle pinning, which can provide a valuable insight for the design of the innovative Co-based superalloys.

\section{Experimental}

The compositions of Co-20Cr-5Al-2.4Hf-1.5Y ${ }_{2} \mathrm{O}_{3}$ (wt\%) and Co-20Cr-5Al (wt\%) were prepared and respectively designated as 5AlCo-ODS and 5AlCo thereafter. The Hf was added into the 5AlCo-ODS to refine the oxide dispersoids, based on the previous work reported by Zhang et al., which has suggested that Hf is effective to reduce the oxide particles size by generating $\mathrm{Y}_{2} \mathrm{Hf}_{2} \mathrm{O}_{7}$ particles [19, 20]. The element powders together with/without $\mathrm{Y}_{2} \mathrm{O}_{3}$ powder were mechanically alloyed (MAed) for $48 \mathrm{~h}$ under argon gas atmosphere by using a planetary type ball mill (Fritsch P-5). The ball/powder weight ratio is 10:1. The MAed powders were then consolidated at 1100 ${ }^{\circ} \mathrm{C}$ and $45 \mathrm{MPa}$ for $2 \mathrm{~h}$ by means of spark plasma sintering (SPS) equipment to produce the pellet type specimens in a dimension of near $15 \mathrm{~mm}$ diameter and $8 \mathrm{~mm}$ length, then followed by hot-rolling at $1200{ }^{\circ} \mathrm{C}$. The final annealing was conducted at $1200{ }^{\circ} \mathrm{C}$ for $1 \mathrm{~h}$ under vacuum of $10^{-4}$ torr.

The crystalline structure of each specimen was detected using X-ray diffraction equipment (XRD, Philips X' Pert PRO). The metallographic analysis was carried out using backscattered electron microscopy (BSE) equipped in electron probe micro-analyzer (EPMA, JEOL JXA-8530F). The grain size and phase constituent were observed by Electron Back-Scattered Diffraction (EBSD) jointed in a scanning electron microscope (SEM, Carl Zeiss Cross Beam 1540 EsB). The distribution of nano-sized oxide particles and microstructure after tensile test were analyzed by using transmission electron microscopy (FEI Titan3 G2 60-300 TEM and JEM-2010), the 
TEM specimens were prepared by focused ion beam milling and FE-SEM imaging (FIB-SEM, JEOL JIB-4600F/HKD). The tensile test was carried out at room temperature and $1000{ }^{\circ} \mathrm{C}$ at a strain rate of $1 \times 10^{-3} \mathrm{~s}^{-1}$. The size of the specimens for tensile tests is $5 \mathrm{~mm}$ in gauge length, $1.2 \mathrm{~mm}$ in width and $0.5 \mathrm{~mm}$ in thickness.

\section{Results}

\subsection{Microstructural characterization}

Co-Cr-Al ternary phase diagram was computed by using the thermodynamic analysis software Pandat [21], and is shown in Fig. 1. The specimen in the chemical composition of Co-20Cr-5Al (wt\%) is mainly composed of two phases at $1100{ }^{\circ} \mathrm{C}$ : the Co solid solution of fcc structure and the CoAl phase of B2 structure. Except for tiny amounts of B2 phase, fcc phase is the dominant.

Fig. 2 shows the BSE images of the metallographic analysis. Due to high aluminum content in the B2 phase, i.e., nearly triple than that in the fcc phase, it's evident to distinguish the B2 and fcc phase through the image contrast at the BSE mode. Both the two samples basically consist of two regions; i.e. the dark region with 0.2-0.4 $\mu \mathrm{m}$ scale and the light grey matrix. Our previous work [22] has proved that the dark region is CoAl phase with B2 structure and the light grey matrix is cobalt solid solution with fcc structure. From the image quality (IQ) maps shown in Fig. 3, the average grain size was turned out $500 \mathrm{~nm}$ for the 5AlCo-ODS and the $1.2 \mu \mathrm{m}$ for the 5AlCo alloy.

\subsection{Oxide particle distribution}

Oxide particle distribution in the 5AlCo-ODS alloy was investigated with the high angle annular dark field and scanning transmission electron microscopy (HAADF-STEM) images and corresponding EDS maps, as shown in Figs. 4 (a) and (b). Due to a high Al concentration in the B2 phase than that in the fcc phase, the B2 phase is easy to be identified from the fcc matrix via corresponding aluminum elemental maps. Fig. 4 (a) shows the results obtained from the B2 phase, in which large amounts of coarse Y-Hf-rich oxides could be confirmed. The Y-Hf particles exist 
in the fcc matrix, as well, as shown in the Fig. 4 (b), but in which the particles are much denser and smaller than that in B2 phase. Since the Y-Hf oxide is the primary dispersoid in the Co-based ODS superallous, it's noticeable to confirm that the fcc phase possesses more particles than the B2 phase through the elemental mappings of $\mathrm{O}, \mathrm{Y}$ and Hf. The coalescence of Hf with a high vacancy in the B2 phase has been verified to be responsible for the coarsening of those Y-Hf oxides with a core-shell structure of $\mathrm{Y}_{2} \mathrm{Hf}_{7} \mathrm{O}_{17}$ type $[19,22]$. Besides, several coarse particles with black contrast could be observed, which are enriched with $\mathrm{Al}$ and $\mathrm{O}$. Our previous results of three dimension atom probe (3DAP) indicated that they are $\mathrm{Al}_{2} \mathrm{O}_{3}$ particles [22].

\subsection{Tensile properties}

The results of tensile properties at room temperature and $1000{ }^{\circ} \mathrm{C}$ are shown in Figs. 5 (a) and (b), respectively. In respect of room temperature, both the samples exhibited high ultimate tensile stress (UTS), i.e., 2.85 GPa in the 5AlCo-ODS and 1.73 GPa in the 5AlCo alloy. However, according to the Fig. 5 (a), a limited plastic deformation with $1.2 \%$ elongation was found in the 5AlCo-ODS sample, while $8.5 \%$ was attained in the 5AlCo. With temperature increasing to the $1000{ }^{\circ} \mathrm{C}$, the UTS values were drastically reduced and the elongation was increased. Namely, the 5AlCo-ODS shows $105.9 \mathrm{MPa}$ UTS and 27\% elongation as well as the 5AlCo presents 36.5 MPa UTS and 55\% elongation, correspondingly.

In order to investigate the fracture mechanism of the samples at room temperature and $1000{ }^{\circ} \mathrm{C}$, microstructure observation on the tensile tested specimens was carried out. Fig. 6 shows the fractography of 5AlCo-ODS after the tensile testing at room temperature. In the magnified image, dimple structure is observed and it dominates the fractured cross-section, suggesting that a plastic deformation occurred. In addition, several larger and deeper holes are found, as shown with the dotted circle in the Fig. 6. Based on the spherical shape with deformed edge, they are supposed to be bigger dimples caused by plastic deformation, in which several coarse grains existed initially.

In the case of $1000{ }^{\circ} \mathrm{C}$, large amounts of cracks at the normal surfaces of the fractured 5AlCo-ODS and 5AlCo samples were observed, as shown in Figs. 7 (b) and 
(c). Even the argon gas was utilized as protective atmosphere during the tensile test at $1000{ }^{\circ} \mathrm{C}$, the cracks were slightly oxidized and become more noticeable with white contrast, as shown with the magnified image in the right bottom of the Fig. 7 (b). The EBSD observation was conducted on the cracks located areas, as shown in Figs. 7 (d), (e), (f) and (j), according to the IQ and corresponding OIM-IPF maps, many voids are found to be located along grain boundaries and grain boundary triple junctions.

\section{Discussion}

\subsection{Stability of metastable fcc phase}

In respect of conventional Co-based alloys, the fcc-to-hcp transformation proceeds during cooling from the solution-treated temperature, and results in a stable hcp $\varepsilon$-phase at room temperature, which is known as fcc/hcp martensitic transformation [23]. Ando et al. [24] reported that Co-4Al-11Cr (wt\%) alloy contains $91 \%$ of $\varepsilon$-martensite at room temperature after cooling from $1200{ }^{\circ} \mathrm{C}$. A volume fraction of $\varepsilon$-martensite $\left(\mathrm{V}_{\mathrm{m}}\right)$ for the Co-20Cr-5Al alloy in the present study can be estimated more than $80 \%$, by extrapolating from $11 \mathrm{Cr}$ to $20 \mathrm{Cr}$ on the basis of Ando's data [24]. However, as shown in Fig. 8, peak height of $\varepsilon$-martensite is adequately weak, and fcc phase is dominant in both the 5AlCo-ODS and the 5AlCo alloy at room temperature. This result means that the phase transformation of fcc-hcp has been suppressed during cooling process, and the fcc phase retained at room temperature can be said to be metastable state.

Huang et al. [25, 26] reported that the $\mathrm{V}_{\mathrm{m}}$ is strongly influenced by the grain size in the Co-Cr-Mo alloy, and the $\mathrm{V}_{\mathrm{m}}$ is relatively low in fine grained alloys but concomitantly increases with increasing grain sizes [25]. In the case of the ultrafine grains of the $500 \mathrm{~nm}$ in the 5AlCo-ODS and the $1.2 \mu \mathrm{m}$ in the 5AlCo, an extremely small $\mathrm{V}_{\mathrm{m}}$ could be estimated if substituting the grain sizes to the function proposed by Huang et al., as shown in Fig. 9. The critical activation energy $(\Delta \mathrm{G})$ for fcc-to-hcp martensitic transformation can be expressed as [27]: 
$\Delta \mathrm{G}=\frac{\mathrm{K}}{\left(\Delta \mathrm{g}+\Delta \mathrm{G}_{\mathrm{Int}}\right)^{4}}$

where $\mathrm{K}$ is a constant connected with the elastic and interfacial energy between the $\varepsilon$-martensitic and fcc phase, $\Delta \mathrm{g}$ is the chemical driving force for martensitic transformation, and $\Delta \mathrm{G}_{\text {Int }}$ is excess energy induced by the Gibbs-Thomson effect, as shown in Eq.(2) [28],

$$
\Delta \mathrm{G}_{\mathrm{Int}}=2 \gamma \mathrm{v}_{\mathrm{m}} / \mathrm{R}
$$

where the $\gamma$ is the interface energy; $\mathrm{v}_{\mathrm{m}}$ is the molar volume of martensite; and $\mathrm{R}$ is the grain radius. It's obvious that the $\Delta \mathrm{G}_{\text {Int }}$ increases with the refining of grain size [29], because decreasing of grain size results in an increase of the volume of interfaces. A negative value of $\Delta \mathrm{g}$ for the fcc-to-hcp transformation in cobalt, i.e., -16 J/mol [30], tends to cancel out the positive value of $\Delta \mathrm{G}_{\mathrm{Int}}$, and thus the total critical activation energy $\Delta \mathrm{G}$ could be increased with increasing of $\Delta \mathrm{G}_{\mathrm{Int}}$ in Co-based alloys. Therefore, higher $\Delta \mathrm{G}$ induced by the ultrafine grain in both the 5AlCo-ODS and the 5AlCo is supposed to be responsible for the stable fcc structure at room temperature. The processes leading to the formation of nano-crystalline structures during ball-milling have been published in reports [31, 32], which is attributed to the high deformation rates in the MA process. Besides, grain boundaries and phase boundaries are decorated with a large number of oxide particles in the 5AlCo-ODS [22]; thus grain coarsening during sintering and annealing processes could be suppressed by the oxides pinning effect in ODS superalloys [4, 33], which results in a smaller grain and more faint hcp peak in the 5AlCo-ODS than that in the 5AlCo. This is obvious by comparing the grain size in Fig. 3 and the (1 0 - $\left.\begin{array}{lll}1 & 1\end{array}\right)_{\text {hcp }}$ peak height before tensile test in Fig. 8.

\subsection{Strengthening by deformed twinning}

As shown in Fig. 5 (a), manufactured specimens exhibited extremely high strength at room temperature: $2.85 \mathrm{GPa}$ for 5AlCo-ODS and 1.73 GPa for 5AlCo. 
These strength levels are much higher than other conventional superalloys. In order to clarify the strengthening mechanism, structure of 5AlCo-ODS was analyzed after the tensile test at room temperature. From the bright field (BF) TEM images shown in Fig. 10, amounts of parallel strips with $100-200 \mathrm{~nm}$ width are found. Furthermore, the selected area diffraction (SAD) pattern of each strip marked with dotted circle has been performed and their results are presented. Based on the SAD patterns, the region 1 and region 2 are proved to be fcc phase. By broadening the range of selected area, a typical fcc twin structure was observed, as shown with the SAD pattern of 3 . Therefore, it's confirmed that the twinning deformation inside metastable fcc phase occurred during the tensile deformation at room temperature. Besides, with a high magnification TEM image, as shown with the bottom BF TEM image in Fig. 10, the twins are decorated with a large number of oxide particles, which further enhances the strength of the 5AlCo-ODS. In addition, TEM observation has been performed for the 5AlCo after the tensile test at $23{ }^{\circ} \mathrm{C}$. As shown in Fig. 11, an obvious twinning could also be observed. Thus, the twinning formation during tensile test was confirmed for the two Co-based alloys. Fig. 12 shows the orientation imaging microscopy-inverse pole figures (OIM-IPF) and corresponding IQ maps of the room temperature tensile tested samples. Based on these images, the area fraction of twins could be measured, which was approximately $20 \%$ in the 5AlCo-ODS and $32 \%$ in the 5AlCo alloys, respectively. This deformation twin plays a crucial role for enhancing the work-hardening, since the fact that twin boundaries act as strong barriers to dislocation slipping $[15,18]$. It has been verified that metals and alloys with low stacking faults energy (SFE) readily deform via twinning [34, 35] and the twinning is one of the typical deformation mode for the $\gamma$-cobalt (fcc), which possesses a low stacking fault energy and facilitates twinning deformation during strain, especially for the ball-milled nanocrystaline cobalt $[15,17]$. In addition, it's known that a strain-induced $\gamma-\varepsilon$ martensitic transformation will take place under the tensile deformation of the metastable $\gamma$-cobalt (fcc) phase $[13,6,36]$. The Shockley partial dislocations at $\{111\}_{\text {fcc }}$ are regarded as an origin for the formation of $\varepsilon$-martensite. This strain-induced $\varepsilon$-martensite may act as strong barriers for blocking dislocation 
[17]. However, this scenario is not available for interpreting the high strength of the Co-based alloys at room temperature, because no obvious increase of hcp diffraction peak was found after tensile test, which is obvious by comparing (1 0 - 11 1) hcp peak height before and after tensile test in Fig. 8.

\subsection{Strengthening by nano-size oxide particles}

Fig. 13 shows the TEM images of the 5AlCo-ODS after tensile test at room temperature. Dislocation motion is found to be pinned by the fine oxide particles, by which the tensile strength of 5AlCo-ODS is enhanced. Based on the following equations proposed by Scattergood and Bacon [37], the oxide particle dispersion strengthening could be quantitatively estimated.

$$
\begin{aligned}
& \sigma_{t h}=\mathrm{A} \frac{M}{2 \pi} \frac{\mathrm{Gb}}{\lambda}\left(\ln \frac{\mathrm{D}}{\mathrm{r}_{0}}+\mathrm{B}\right) \\
& \lambda=1.25 \ell_{\mathrm{s}}-2 \mathrm{r}_{\mathrm{s}} \\
& \ell_{\mathrm{s}}=\sqrt{\frac{2 \pi \overline{\mathrm{r}^{3}}}{3 f \bar{r}}} \\
& \mathrm{r}_{\mathrm{s}}=\frac{\pi \overline{r^{2}}}{4 \bar{r}}
\end{aligned}
$$

where the $\sigma_{t h}$ is the threshold stress and corresponds to the oxide particle-hardening stress; the $\lambda$ is average face-to-face distance between two particles; $M$ is the Taylor factor (3.06); $\mathrm{G}$ is the shear modulus and equals to $75 \mathrm{GPa}$ at room temperature; $\mathrm{b}$ is the magnitude of the Burgers vector $\left(2.48 \times 10^{-10} \mathrm{~m}\right)$; $\mathrm{A}$ and $\mathrm{B}$ are constants and are taken as 1.06 and 0.65 , respectively; $r_{0}$ is the inner cut-off radius of a dislocation core (b-3b); $\mathrm{D}$ is harmonic mean of $\lambda$ and $2 r_{s} ; r_{s}$ is the average particles radius: $8 \mathrm{~nm}$ in fcc phase and $11 \mathrm{~nm}$ in $\mathrm{B} 2$ phase; $\ell_{s}$ is the average center to center distance; $\mathrm{f}$ is the volume fraction of the dispersed particles: 0.0217 in the fcc phase and 0.0257 in the B2 phase. Above distribution of the oxide particles in fcc phase and B2 phase was derived by analyzing TEM images and the detailed results are exhibited in Fig. 14. The calculation for $\sigma_{t h}$ is $629 \mathrm{MPa}$ in the $\mathrm{B} 2$ phase as well as $711 \mathrm{MPa}$ in the fcc phase. According to the previous report [22] that volume fraction of the fcc 
and the B2 phase in the 5AlCo-ODS sample are close to $90 \%$ and $10 \%$, respectively, the oxide particle dispersion strengthening in the 5AlCo-ODS superalloy was approximated to be $703 \mathrm{MPa}$ at room temperature. Strength increment in the 5AlCo-ODS from the non-ODS 5AlCo reaches approximately 1 GPa. In 5AlCo-ODS, therefore, the other effect such as grain boundary (GB) strengthening could work effectively at room temperature, because 5AlCo-ODS contains finer grain size than 5AlCo, as shown in the Fig. 3.

\subsection{Strengthening by grain boundary}

The well-known Hall-Petch strengthening model was used to illustrate the relation between the mechanical strength and grain size, which could be expressed as follow [38],

$\sigma_{\mathrm{y}}=\sigma_{0}+\mathrm{kd}^{-1 / 2}$

where $\sigma_{\mathrm{y}}$ is the yield strength, $\sigma_{0}$ is the friction stress, $k$ is the Hall-Petch slope, $\mathrm{d}$ is the grain size. Due to a limited research in the Co-20Cr-Al (wt\%) system, no detailed values of $\sigma_{0}$ and $k$ can be accessed for the Co-based alloys. In order to derive those values, we cited the $\sigma_{0}$ and $k$ in the $\mathrm{Ni}-20 \mathrm{Cr}$ (wt\%) (Small addition of $\mathrm{Al}$ ) system, since both the two systems are fcc structure and the Ni possesses a close atom size with Co. Namely, the $\sigma_{0}$ and $k$ in the Co-20Cr-5Al (wt\%) alloys are approximately equal to $254 \pm 0.01 \mathrm{MPa}$ and $622 \pm 0.02 \mathrm{MPa} \cdot \mu \mathrm{m}^{1 / 2}$, respectively [39].

In respect of the grain size $d$, since both samples are composed of normal grains and deformation twins, the application of Hall-Petch model should be separated into two parts, in which a different effective grain size should be adopted. For the part of twins, since the twin boundary works as like grain boundary to block the motion of dislocation, the Hall-Petch strengthening model was also considered to be used to quantify the relation between the mechanical strength and deformation twins. Gray et al. [40] proposed that the deformation twinning could improve the strain-hardening rate via Hall-Petch type hardening mechanism, since the twinning divided grains and decreased the effective slip distance. The strength of deformation twins has been 
calculated and the results were found to match quantitatively with the Hall-Petch grain size strengthening by Salem et al. [41]. Therefore, the total GB strength in the Co-based alloys could be shown with next relationship:

$\sigma=\sigma_{\mathrm{n}} \cdot \mathrm{V}_{\mathrm{n}}+\sigma_{\mathrm{T}} \cdot \mathrm{V}_{\mathrm{T}}$

in which $\sigma$ is total GB strength; $\sigma_{\mathrm{n}}$ and $\mathrm{V}_{\mathrm{n}}$ mean the normal GB strength and the volume fraction of the normal grains in matrix; $\sigma_{\mathrm{T}}$ and $\mathrm{V}_{\mathrm{T}}$ are corresponding GB strength and volume fraction coming from the twins.

It's easy to obtain the normal grain boundary strength $\left(\sigma_{n}\right)$ with Eq. (7), since the average grain size has been measured to be $500 \mathrm{~nm}$ in the 5AlCo-ODS and $1.2 \mu \mathrm{m}$ in the 5AlCo alloys. In the case of twin boundary strengthening, if both the twin density and size are known, the calculation of deformed twins strengthening is fairly straight forward, as well. Based on the OIM-IPF maps and IQ maps in the Fig. 12, the proportion of twins could be measured to be $20 \%$ in the 5AlCo-ODS and $32 \%$ in the 5AlCo alloys, respectively. In respect of the calculation of twin size (d), since the motion direction of dislocation in the twins cannot be known, it's difficult to confirm that the dislocation sliding is parallel to the long twin boundary or just perpendicular to it. Therefore, based on the observation of TEM, both the short and long distance between twin boundaries have been measured and the results are listed in Table 1. Besides, the corresponding Hall-Petch strength with the two distances has been calculated and introduced in the Table 1, which was named with $\sigma_{S}$ and $\sigma_{L}$, respectively. And then the $\sigma_{\mathrm{T}}$ was supposed to approximately equal to the average of the $\sigma_{\mathrm{S}}$ and $\sigma_{\mathrm{L}}$. Table 2 exhibited the calculated GB strength come from the normal grains and twins. Thus, the difference of the GB strength could be found to be 299 $\mathrm{MPa}$, which is quite consistent with the value derived from the UTS difference (297 $\mathrm{MPa})$ in the 5AlCo-ODS and the 5AlCo sample. Besides, if we use the UTS strength to subtract the GB strength and the ODS strengthening, the solid solution strength in the two samples could be derived, which equals to $673 \mathrm{MPa}$ in the 5AlCo-ODS and $676 \mathrm{MPa}$ in the 5AlCo alloys. Consequently, a summarization for the analysis of the UTS strength at room temperature could be produced, as listed in Fig. 15. 
However, at elevated temperature of $1000{ }^{\circ} \mathrm{C}$, the UTS of both alloys were decreased significantly. Based on the investigation on the fractured specimens, as shown in the Fig. 7, a large number of voids are located along grain boundaries and grain boundary triple junctions, which is a clear evidence for the occurrence of grain boundary deformation (GBD). At elevated temperatures, deformation could be accelerated since the sliding and atomic diffusion through grain boundaries and results in the formation of cracks along the grain boundaries. It's one of the main failure modes for the ODS superalloys which possess ultrafine grains [42]. Since both the alloys possess ultrafine grain size, i.e., the $500 \mathrm{~nm}$ in the 5AlCo-ODS and the 1.2 $\mu \mathrm{m}$ in the 5AlCo, the grain boundary density would be increased significantly and resulted in a large motion tendency for the GBD. Therefore, the drastic decrease on the UTS is attributed to the GBD at elevated temperature. However, as confirmed by Sugino et al.[43] that the GBD could be suppressed in ODS steel relative to iron as a result of the pinning of the dislocation movement by the dispersed oxide particles, the large amounts of Y-Hf-O dispersoids in the 5AlCo-ODS superalloy was proposed to play certain roles on restricting the GBD and resulted in a higher tensile strength than the $5 \mathrm{AlCo}$ samples at $1000{ }^{\circ} \mathrm{C}$ even with a much finer grain size.

In the case of the 5AlCo-ODS superalloy, the low ductility at room temperature is detrimental to the ability of plastic deformation. The limited plasticity was attributed to the dispersion of oxide particles and the fine grains. In addition, the UTS value of 105.9 $\mathrm{MPa}$ at $1000{ }^{\circ} \mathrm{C}$ is still far less than our target, which was mainly caused by the small grain size. Dispersed oxides are essential for our design, thus the enlargement of grain size is considered to be applicable to improve the plasticity at low temperature and the UTS at $1000{ }^{\circ} \mathrm{C}$. Our previous study on Ni-based ODS superalloys [44] proves that zone annealing is useful to produce directionally recrystallized grains, which is capable for adjusting grain size to reach a good balance between strength and ductility. 


\section{Conclusions}

A comprehensive experimental investigation has been performed to characterize tensile properties of the novel Co-20Cr-5Al-2.4Hf-1.5 $\mathrm{Y}_{2} \mathrm{O}_{3}$ (wt\%) ODS superalloy. Specific conclusions are drawn as follows:

(1) The 5Al Co-based ODS superalloy contains basically two phases: a Co-based solid solution with fcc structure and a CoAl phase with B2 structure. The Co-based ODS superalloy is governed by the metastable fcc phase rather than $\varepsilon$-martensite at room temperature due to the ultrafine grain with $500 \mathrm{~nm}$, resulting from the ball-milling and the pinning effect of Y-Hf oxide particles. Y-Hf oxide particles distributed inside the metastable fcc phase are denser and smaller than that in the B2 phase.

(2) The 5AlCo-ODS superalloy and the 5AlCo alloy without oxide particles exhibit high tensile strength with $2.85 \mathrm{GPa}$ and $1.73 \mathrm{GPa}$ at room temperature, which are associated with the strain-induced twins deformation of the metastable fcc phase. The distribution of fine Y-Hf oxide particles in the 5AlCo-ODS superalloy results in an improvement of strength with $703 \mathrm{MPa}$.

(3) During the tensile process of $1000{ }^{\circ} \mathrm{C}$, since the ultrafine grain size in the both alloys, an easy grain boundary deformation occurred and resulted in the reduction of UTS values to be 105.9 MPa in the 5AlCo-ODS superalloy and $36.5 \mathrm{MPa}$ in the 5AlCo alloy, respectively. The pinning effect of the Y-Hf oxide particles in the 5AlCo-ODS superalloy is responsible for the relatively high UTS value than the 5AlCo alloy at $1000{ }^{\circ} \mathrm{C}$.

\section{Acknowledgments}

This work is supported by Grant-in-Aid for Scientific Research (B), 24360282, Japan Society for the Promotion of Science (JSPS). H. Yu is grateful to the China Scholarship Council (CSC) for the provision of a scholarship. The authors would also like to acknowledge the "Joint-use Facilities: Laboratory of Nano-Micro Material Analysis”, Hokkaido University. 


\section{References}

[1] D. Coutsouradis, A. Davin, M. Lamberigts, Cobalt-based superalloys for applications in gas turbines, Mater. Scin. Eng. 88 (1987) 11-19.

[2] Bilbrey, Joseph H, Cobalt: a materials survey, U.S. Bureau of Mines, 1962, pp. 3-5.

[3] S. Ukai, M. Fujiwara, Perspective of ODS alloys application in nuclear environments, J. Nucl. Mater. 307-311 (2002) 749-757.

[4] S. Ukai, T. Kaito, S. Ohtsuka, T. Narita, M. Fujiwara, T. Kobayashi, Production and properties of nano-scale oxide dispersion strengthened (ODS) 9Cr martensitic steel claddings, ISIJ int. 43 (2003) 2038-2045.

[5] L. Zhang, X.H. Qu, X.B. He, R.U. Din, H.S. Liu, M.L. Qin, H.M. Zhu, Microstructural characterization of Co-based ODS alloys, J. Mater. Eng. Perform. 21 (2012) 2487-2494.

[6] S.H. Zangeneh, H. Farhangi, Influence of service-induced microstructural changes on the failure of a cobalt-based superalloy first stage nozzle, Mater. Des. 31 (2010) 3504-3511.

[7] J. Sato, T. Omori, K. Oikawa, I. Ohnuma, R. Kainuma, K. Ishida, Cobalt-base high-temperature alloys, Science 312 (2006) 90-91.

[8] L. Klein, A. Bauer, S. Neumeier, M. Goken, S.Virtanen, High temperature oxidation of $\gamma / \gamma$ '-strengthened Co-base superalloys, Corros. Sci. 53 (2011) 2027-2034.

[9] K. Takezawa, S. Ukai, S. Hayashi, Microstructure control of Co-base ODS alloys, Adv. Mater. Res. 239-242 (2011) 864-867.

[10] S. Ukai, T. Okuda, M. Fujiwara, T. Kobayashi, S. Mizuta, H. Nakashima, Characterization of high temperature creep properties in recrystallized 12Cr-ODS ferritic steel claddings, J. Nucl. Sci. Technol. 39 (2002) 872-879.

[11] Y. Sugino, S. Ukai, B. Leng, Q.X. Tang, S. Hayashi, T. Kaito, S. Ohtsuka, Grain boundary deformation at high temperature tensile tests in ODS ferritic steel, ISIJ International, 51 (6) (2011), 982-986.

[12] S.F. Li, Z.J Zhou, M. Li, M. Wang, G.M Zhang, Microstructure characterization and tensile properties of 18Cr-4Aloxide dispersion strengthened ferritic steel, J. Alloys Comp., 648 (2015) 39-45.

[13] Bibby MJ, Gordon Parr J. Cobalt 20 (1963) 111.

[14] J.Y Huang, Y.Q Wu, H.Q Ye, Appl. Phys . Lett 66 (1995) 308.

[15] J. Sort, J. Nogues, S. Surinach, MD Baro. Phil. Mag 83 (2003) 439.

[16] X. Wu, N. Tao, Y. Hong, G. Liu, B. Xu, J. Lu, K. Lu, Strain-induced grain refinement of cobalt during surface mechanical attrition treatment, Acta Mater. 53 (2005) 681-691.

[17] X. Wu, N. Tao, Y. Hong, J. Lu, K. Lu, $\gamma \rightarrow \varepsilon$ martensite transformation and twinning deformation in fcc cobalt during surface mechanical attrition treatment, Scri. Mater, 52 (2005) 547-551.

[18] L. Remy, A. Pineau, Twinning and strain-induced F.C.C.-H.C.P. transformation on the mechanical properties of Co-Ni-Cr-Mo alloys, Mater. Sci. Eng. 26 (1976) 123-132. 
[19] L. Zhang, S. Ukai, T. Hoshino, S. Hayashi, X. Qu, $\mathrm{Y}_{2} \mathrm{O}_{3}$ evolution and dispersion refinement in Co-base ODS alloys, Acta Mater. 57 (2009) 3671-3682.

[20] T. Sasaki, K. Takazawa, S. Ukai, N. Oono, S. Hayashi, Effect of heat treatment on the hardness and microstructure in Co-3Al-1.5Y2O3-1.2Hf ODS alloy Mater. Sci. Eng. A 601 (2014) 139-144.

[21] W. Cao, S.-L. Chen, F. Zhang, K. Wu, Y. Yang, Y.A. Chang, R. Schmid-Fetzer, W.A. Oates, PANDAT software with PanEngine, PanOptimizer and PanPrecipitation for multi-component phase diagram calculation and materials property simulation, Calphad 33 (2009) 328-342.

[22] H. Yu, S. Ukai, N. Oono, T. Sasaki, Microstructure characterization of Co-20Cr-(5, 10)Al oxide dispersion strengthened superalloys, Mater. Charact. 112(2016)188-196.

[23] I. Marek, D. Vojtech, A. Michalcova, T.F. Kubatik, The structure and mechanical properties of high-strength bulk untrafine-grained cobalt prepared using high-energy ball milling in comination with spark plasm sintering, materials (2016) 9, 391.

[24] K. Ando, T. Omori, J. Sato, Y. Sutou, K. Oikawa, R. Kainuma, K. Ishida, Effect of alloying elements on fcc/hcp martensitic transformation and shape memory properties in Co-Al alloys, Materials Transactions, 47 (2006) 2381-2386.

[25] P. Huang, H.F. Lopez, Athermal $\varepsilon$-martensite in a Co-Cr-Mo alloy: grain size effects, Materials Letters 39 (1999) 249-253.

[26] P. Huang, H.F. Lopez, strain induced $\varepsilon$-martensite in a Co-Cr-Mo alloy: grain size effects, Materials Letters 39 (1999) 244-248.

[27] Zhao, X.; Liang, Y.; Hu, Z.; Liu, B. Thermodynamic interpretation of the martensitic transformation in ultrafine-Fe(N) particles. Jpn. J. Appl. Phys. 1996, 35, 4468-4473.

[28] Sarkar, S.; Bansal, C.; Chatterjee, A. Gibbs-Thomson effect in nanocrystalline Fe-Ge. Phys. Rev. B 2000, 62, 3218-3222.

[29] Zhao, X.Q.; Veintemillas-Verdaguer, S.; Bomati-Miguel, O.; Morales, M.P.; Xu, H.B. Thermal history dependence of the crystal structure of Co fine particles. Phys. Rev. B 2005, 71.

[30] Ray, A.E.; Smith, S.R.; Scofield, J.D. Study of the phase transformation of cobalt. J. Phase Equilib. 1991, 12, 644-647.

[31] Nazari, A.; Zakeri, M. Modeling the mean grain size of synthesized nanopowders produced by mechanical alloying. Ceram. Int. 2013, 39, 1587-1596.

[32] Abdellahi, M.; Bahmanpour, M. Rapid synthesis of nanopowders in high energy ball milling; Optimization of milling parameters. Ceram. Int. 2015, 41, 1631-1639.

[33] S. Ukai, S. Ohtsuka, Nano-mesoscopic structure control in 9Cr-ODS ferritic steels, Energy Mater. 2(1) (2007) 26-35.

[34] Y. Li, Y.H. Zhao, W. Liu, C. Xu, Z. Horita, etc, Influence of grain size on the density of deformation twins in Cu-30\%Zn alloy, Mater. Sci. Eng. A 527 (2010) 3942-3948.

[35] J.A. Venables, Philos. Mag. 6 (1961) 379-396. 
[36] Bibring H, Sebilleau F, Buckle CJ. Inst Metals 1958-1959;87:71.

[37] R.O. Scattergood, D.J. Bacon, Phil. Mag. A 31(1975) 179-198.

[38] R.W Armstrong, I. Codd, R.N. Douthwaite, N.J. Petch, Phil. Mag. 7 (1962) 45.

[39] R. DiDomizio, M.F. Gigliotti, J.S. Marte, PR. Subramanian, V. Valitov, Evaluation of a Ni-20Cr alloy processed by multi-axis forging, Materials Science Forum, 503-504 (2006) 793-798.

[40] Gray III GT. J Phys IV France 7 (1997) 423.

[41] A.A. Salem, S.R. Kalidindi, R.D. Doherty, Strain hardening regimes and microstructure evolution during large strain compression of high purity titanium, Scripta Mater. 46 (6) (2002) 419-423.

[42] Y. Sugino, S. Ukai, B. Leng, Q.X. Tang, S. Hayashi, T. Kaito, S. Ohtsuka, Grain boundary deformation at high temperature tensile tests in ODS ferritic steel, ISIJ International, Vol. 51 (2011), No. 6, pp. 982-986.

[43] Y. Sugino, S. Ukai, B. Leng, N. Oono, S. Hayashi, T. Kaito, S. Ohtsuka, Grain boundary sliding at high temperature deformation in cold-rolled ODS ferritic steels, J. Nucl. Mater. 452 (2014) 628-632.

[44] Y. Sugino, S. Ukai, S. Hayashi, Q.X. Tang, B. Leng, Directional recrystallization of ODS alloys by means of zone annealing, J. Nucl. Mater. 417 (2011) 171-175. 


\section{Table \& Figure captions list}

Table 1 Measured distance in twin grains and corresponding twin boundary strength calculated with Hall-Petch model.

Table 2 GB strength obtained from the normal grains and the twins.

Fig. 1 The ternary Co-Cr-Al phase diagram calculated with Pandat software at $1100{ }^{\circ} \mathrm{C}$.

Fig. 2 BSE images obtained from the 5AlCo-ODS (a) and the 5AlCo (b) samples.

Fig. 3 IQ maps obtained from the 5AlCo-ODS (a) and the 5AlCo (b) samples.

Fig. 4 HAADF-STEM images of nanoscale particles in the 5AlCo-ODS alloy and corresponding EDS elemental maps of Co, Cr, Al, Hf, Y and O, in which (a) and (b) are obtained from the B2 and the fcc phase, respectively.

Fig. 5 Stress-strain curves of the 5AlCo-ODS and the 5AlCo samples at room temperature (a) and $1000{ }^{\circ} \mathrm{C}$ (b).

Fig. 6 Fractured cross-sections of the 5AlCo-ODS superalloy at room temperature.

Fig. 7 (a) illustrates the $1000{ }^{\circ} \mathrm{C}$ tensile tested specimen and the SEM/EBSD observation areas; (b), (d) and (f) are the SEM image, IQ and OIM-IPF maps obtained from the 5AlCo-ODS sample, respectively; (c), (e) and (j) show the corresponding results in the 5AlCo sample.

Fig. 8 Comparison between the XRD results of the samples before and after tensile test at $23{ }^{\circ} \mathrm{C}$, (a) is 5AlCo-ODS superalloy and (b) is 5AlCo alloy.

Fig. 9 Volume fraction of athermal $\varepsilon$-phase as a function of grain size.

Fig. 10 TEM images and corresponding selected area diffraction (SAD) patterns of twins in the 5AlCo-ODS superalloy after tensile test at room temperature.

Fig. 11 TEM images of deformation twins in the 5AlCo alloy after tensile test at room temperature.

Fig. 12 OIM-IPF maps and corresponding IQ maps obtained from the 5AlCo-ODS (a) and the 5AlCo samples (b). The grain boundaries and twin boundaries have been marked with blue lines by the TSL OIM Analysis 7.0 software.

Fig. 13 TEM images of the 5AlCo-ODS superalloy after tensile test at room temperature.

Fig. 14 Oxide particles distribution of the fcc and B2 phase on the 5AlCo-ODS superalloy.

Fig. 15 Summarization for the components of the UTS in the 5AlCo-ODS and the 5AlCo samples. 
Table 1 Measured distance in twin grains and corresponding twin boundary strengthening calculated with Hall-Petch model.

\begin{tabular}{|c|c|c|c|c|}
\hline Alloys & Short distance $/ \mu \mathrm{m}$ & $\sigma_{\mathrm{S}} / \mathrm{MPa}$ & Long distance $/ \mu \mathrm{m}$ & $\sigma_{\mathrm{L}} / \mathrm{MPa}$ \\
\hline 5AlCo-ODS & 0.03 & 3845 & 1.20 & 822 \\
\hline 5AlCo & 0.08 & 2453 & 1.46 & 769 \\
\hline
\end{tabular}

Table 2 GB strength obtained from the normal grains and the twins.

\begin{tabular}{|c|c|c|c|c|c|c|c|}
\hline Alloy & $\sigma_{\mathrm{n}} / \mathrm{MPa}$ & $\mathrm{V}_{\mathrm{n}} / \%$ & $\sigma_{\mathrm{n}} \cdot \mathrm{V}_{\mathrm{n}}$ & $\sigma_{\mathrm{T}} / \mathrm{MPa}$ & $\mathrm{V}_{\mathrm{T}} / \%$ & $\sigma_{\mathrm{T}} \cdot \mathrm{V}_{\mathrm{T}}$ & $\sigma / \mathrm{MPa}$ \\
\hline 5AlCo-ODS & 1134 & 80 & 907 & 2334 & 20 & 467 & 1374 \\
\hline 5AlCo & 822 & 68 & 559 & 1611 & 32 & 516 & 1075 \\
\hline
\end{tabular}




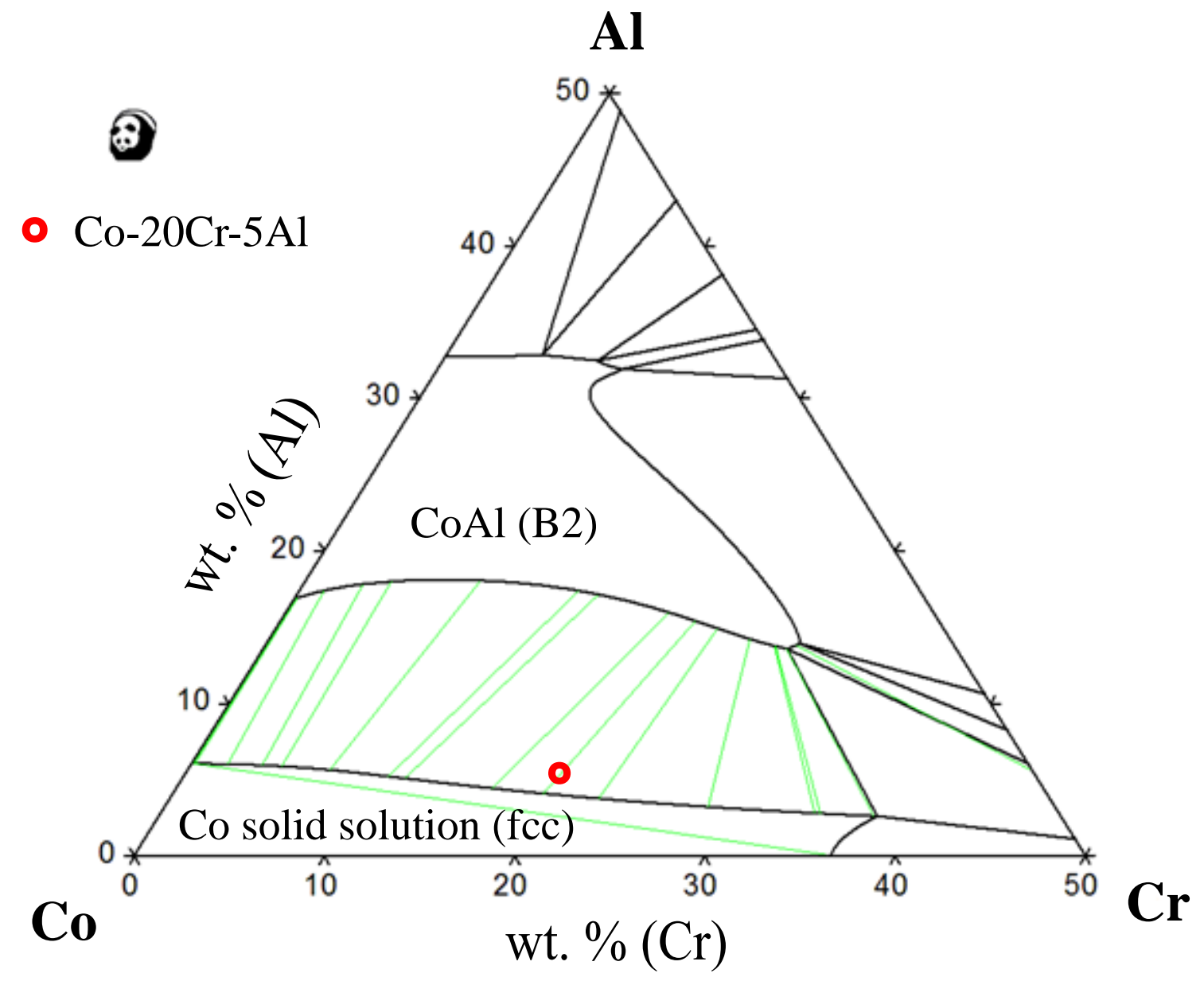

Fig. 1 The ternary Co-Cr-Al phase diagram calculated with Pandat software at $1100{ }^{\circ} \mathrm{C}$. 

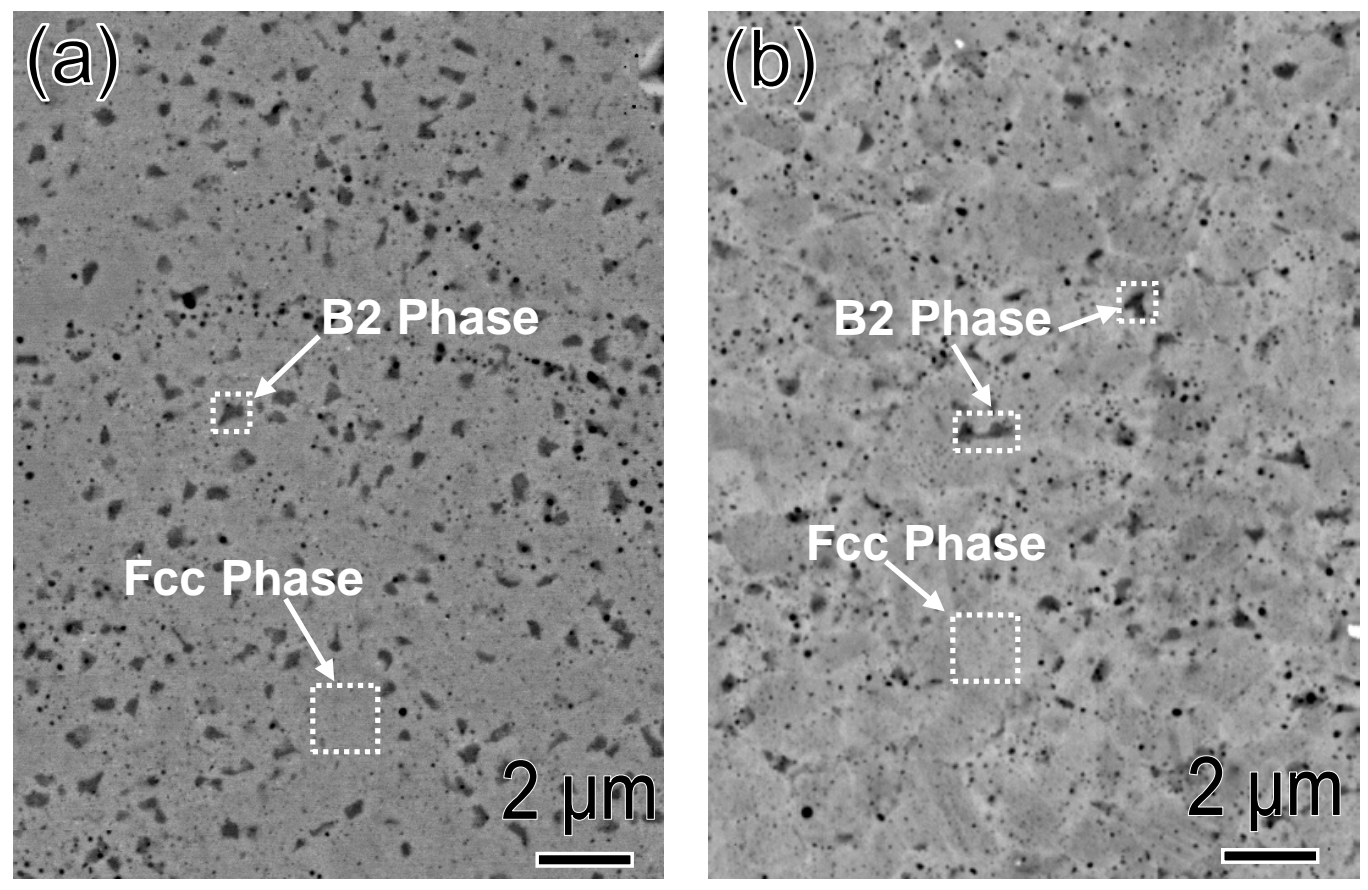

Fig. 2 BSE images obtained from the 5AlCo-ODS (a) and the 5AlCo (b) samples. 

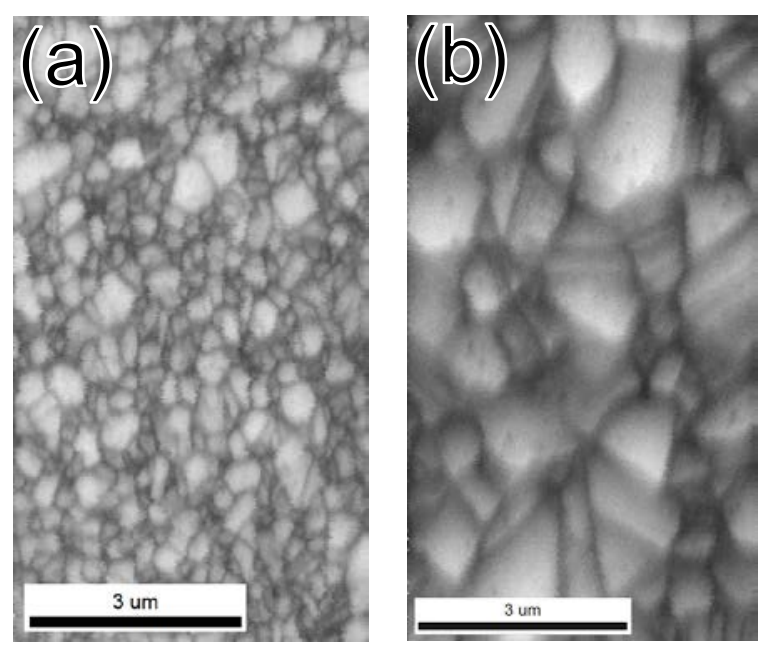

Fig. 3 IQ maps obtained from the 5AlCo-ODS (a) and the 5AlCo (b) samples. 

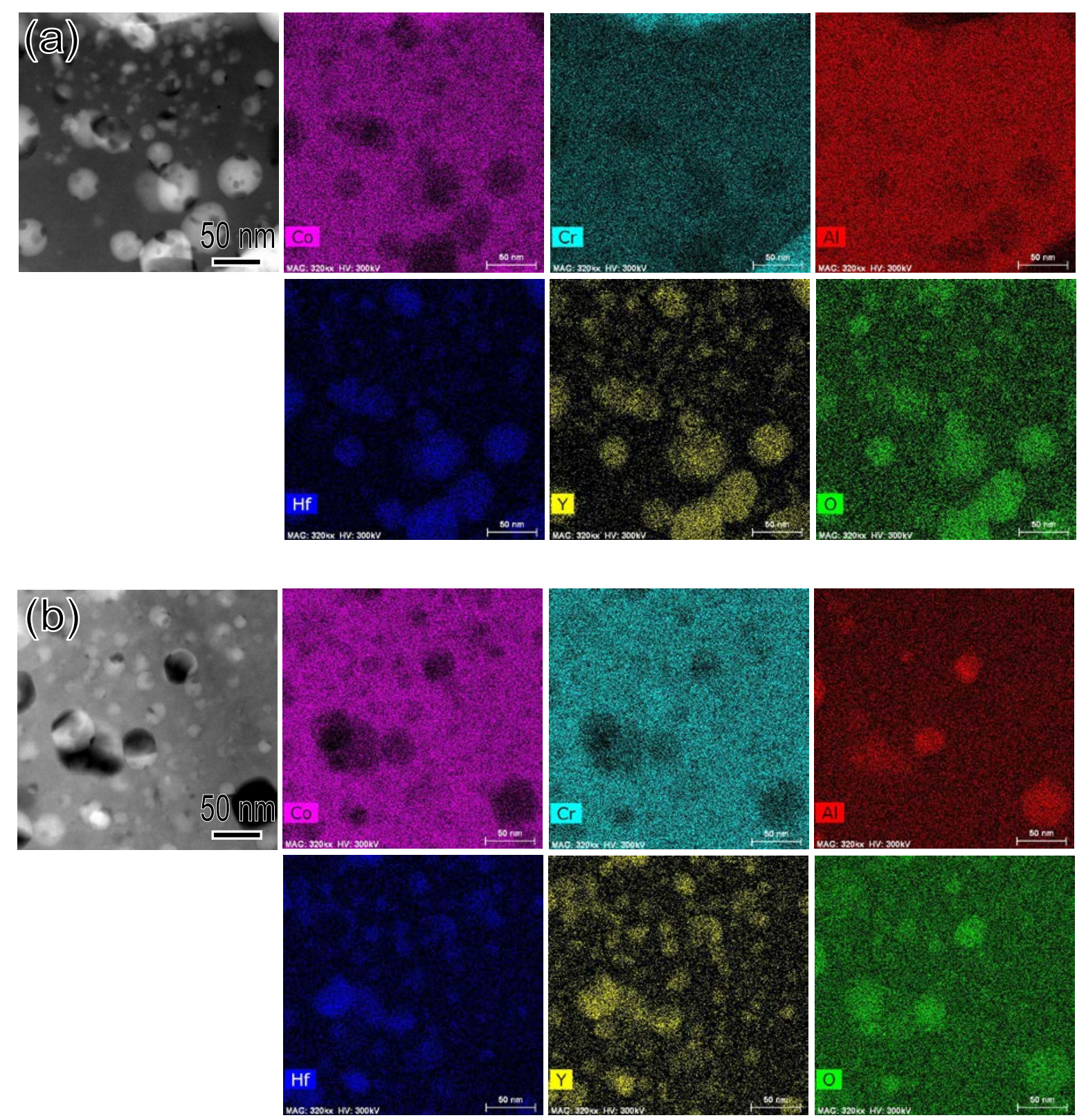

Fig. 4 HAADF-STEM images of nanoscale particles in the 5AlCo-ODS alloy and corresponding EDS elemental maps of $\mathrm{Co}, \mathrm{Cr}, \mathrm{Al}, \mathrm{Hf}, \mathrm{Y}$ and $\mathrm{O}$, in which (a) and (b) are obtained from the $\mathrm{B} 2$ and the fcc phase, respectively. 

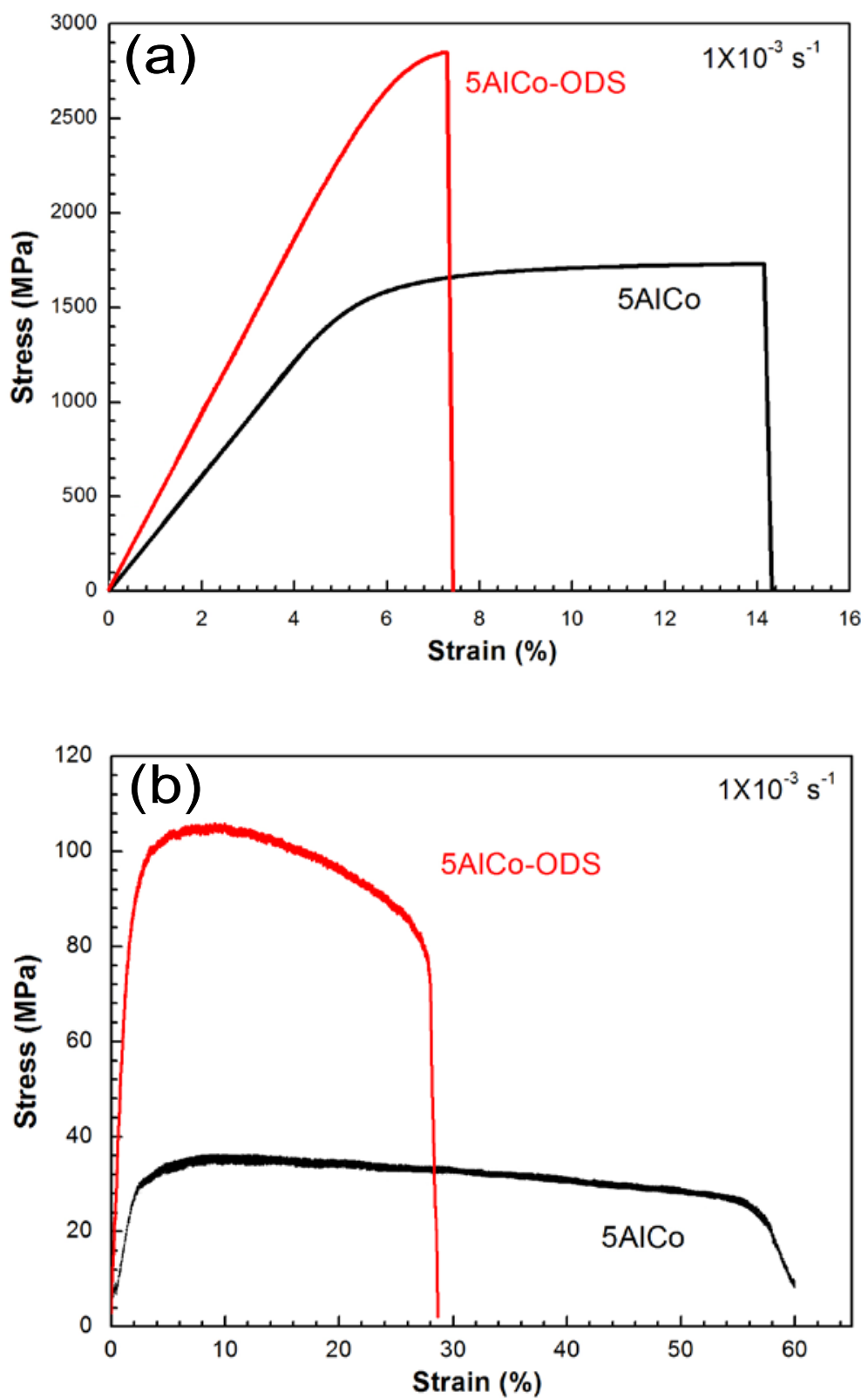

Fig. 5 Stress-strain curves of the 5AlCo-ODS and the 5AlCo samples at room temperature (a) and $1000{ }^{\circ} \mathrm{C}$ (b). 


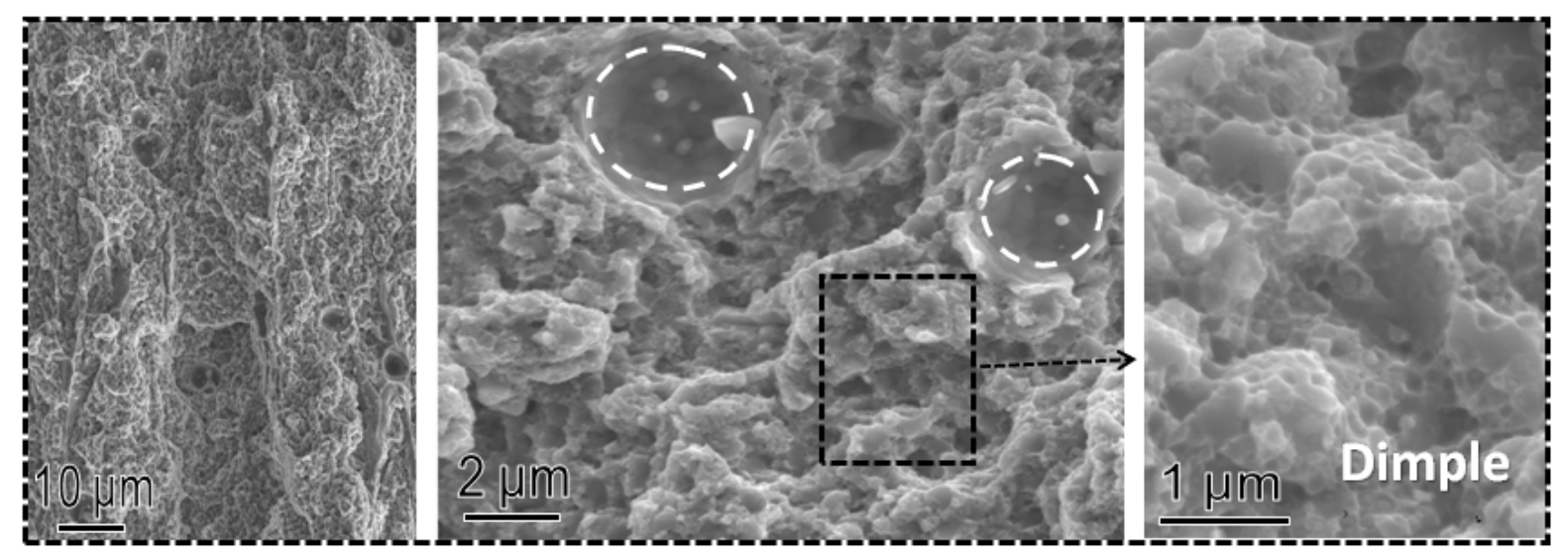

Fig. 6 Fractured cross-sections of the 5AlCo-ODS superalloy at room temperature. 


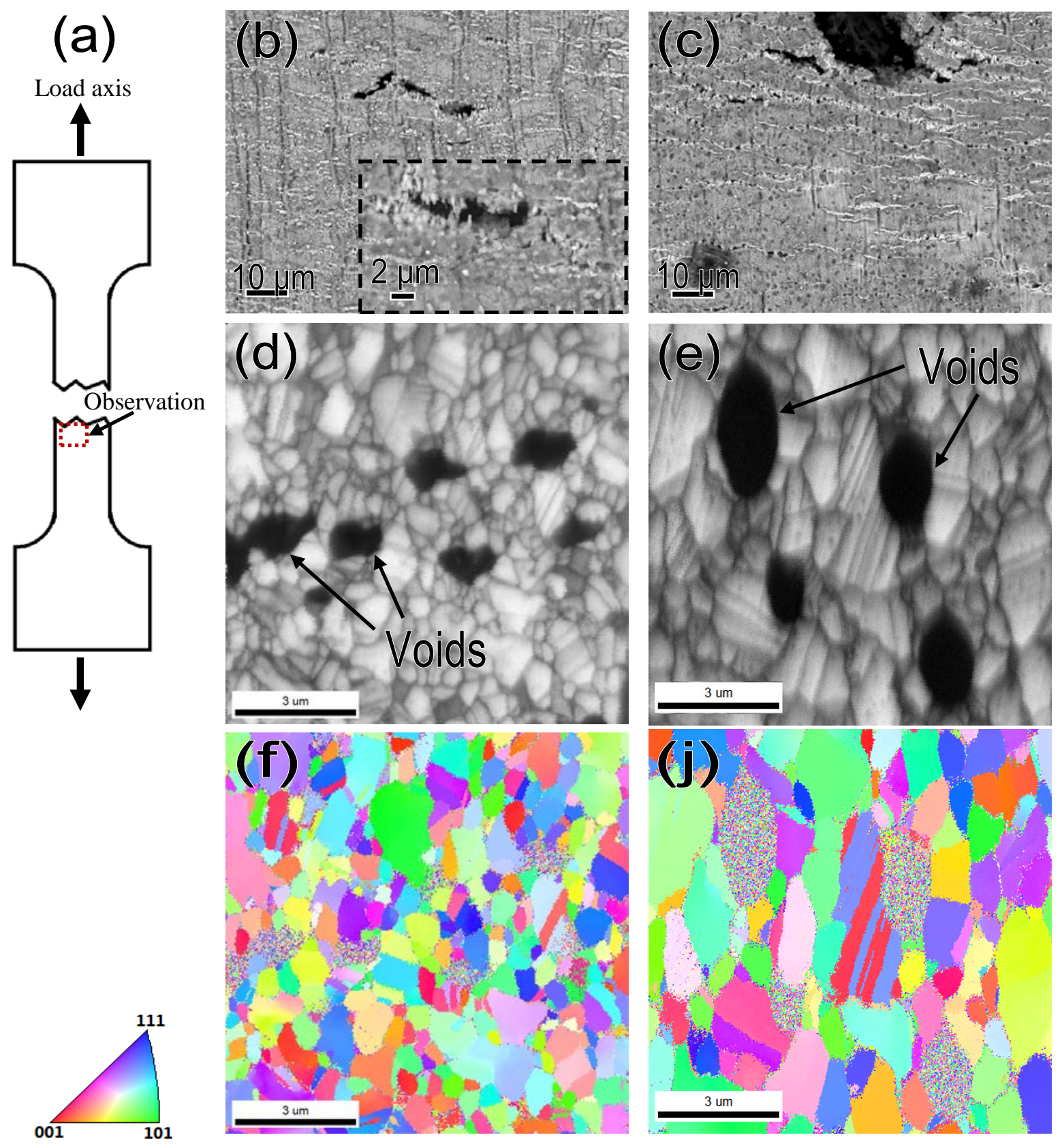

Fig. 7 (a) illustrates the $1000{ }^{\circ} \mathrm{C}$ tensile tested specimen and the SEM/EBSD observation areas; (b), (d) and (f) are the SEM image, IQ and OIM-IPF maps obtained from the 5AlCo-ODS sample, respectively; (c), (e) and (j) show the corresponding results in the 5AlCo sample. 

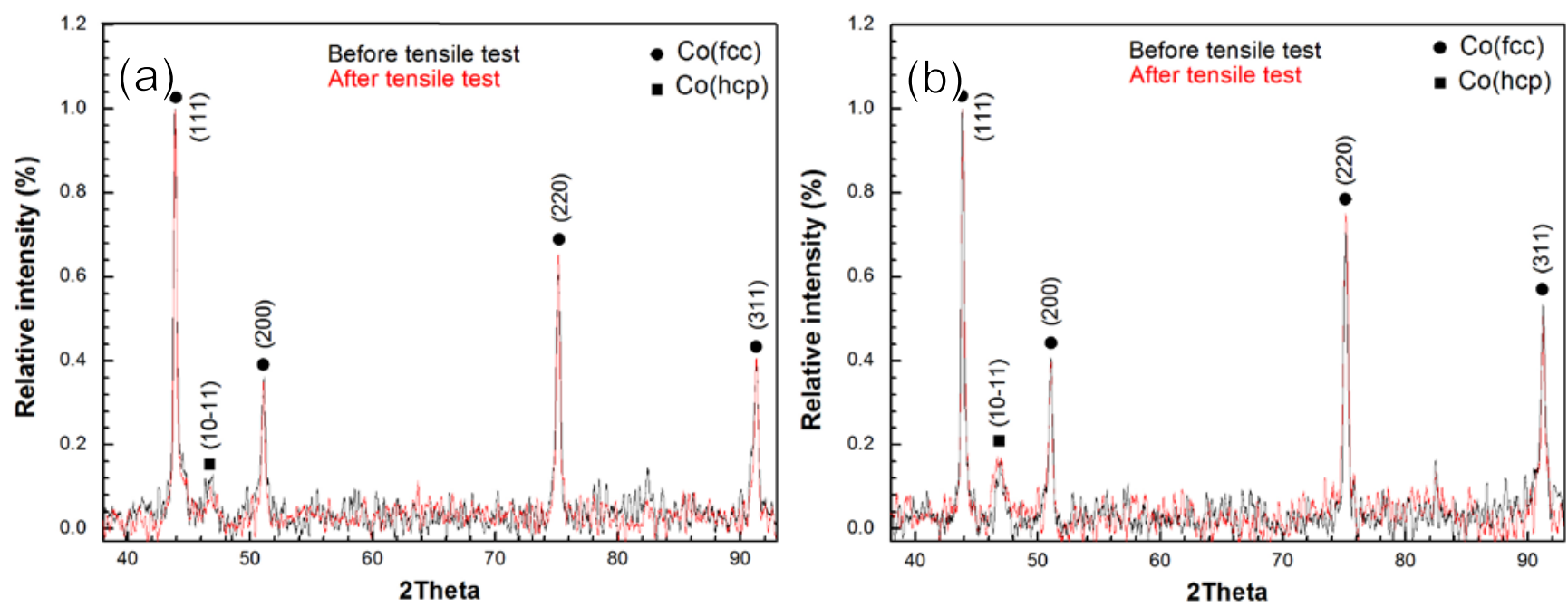

Fig. 8 Comparison between the XRD results of the samples before and after tensile test at $23{ }^{\circ} \mathrm{C}$, (a) is 5AlCo-ODS superalloy and (b) is 5AlCo alloy. 


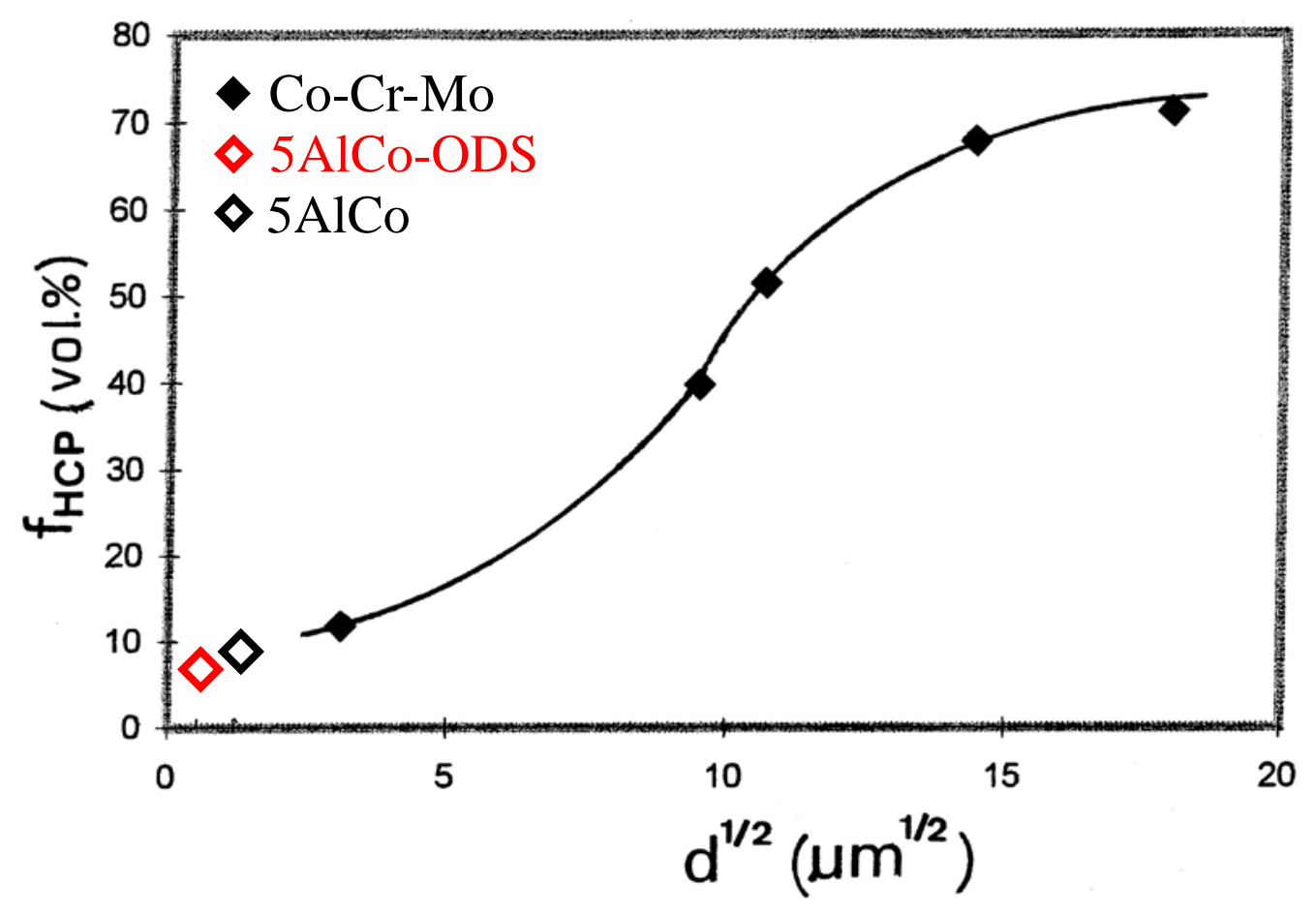

Fig. 9 Volume fraction of athermal $\varepsilon$-phase as a function of grain size [25]. 

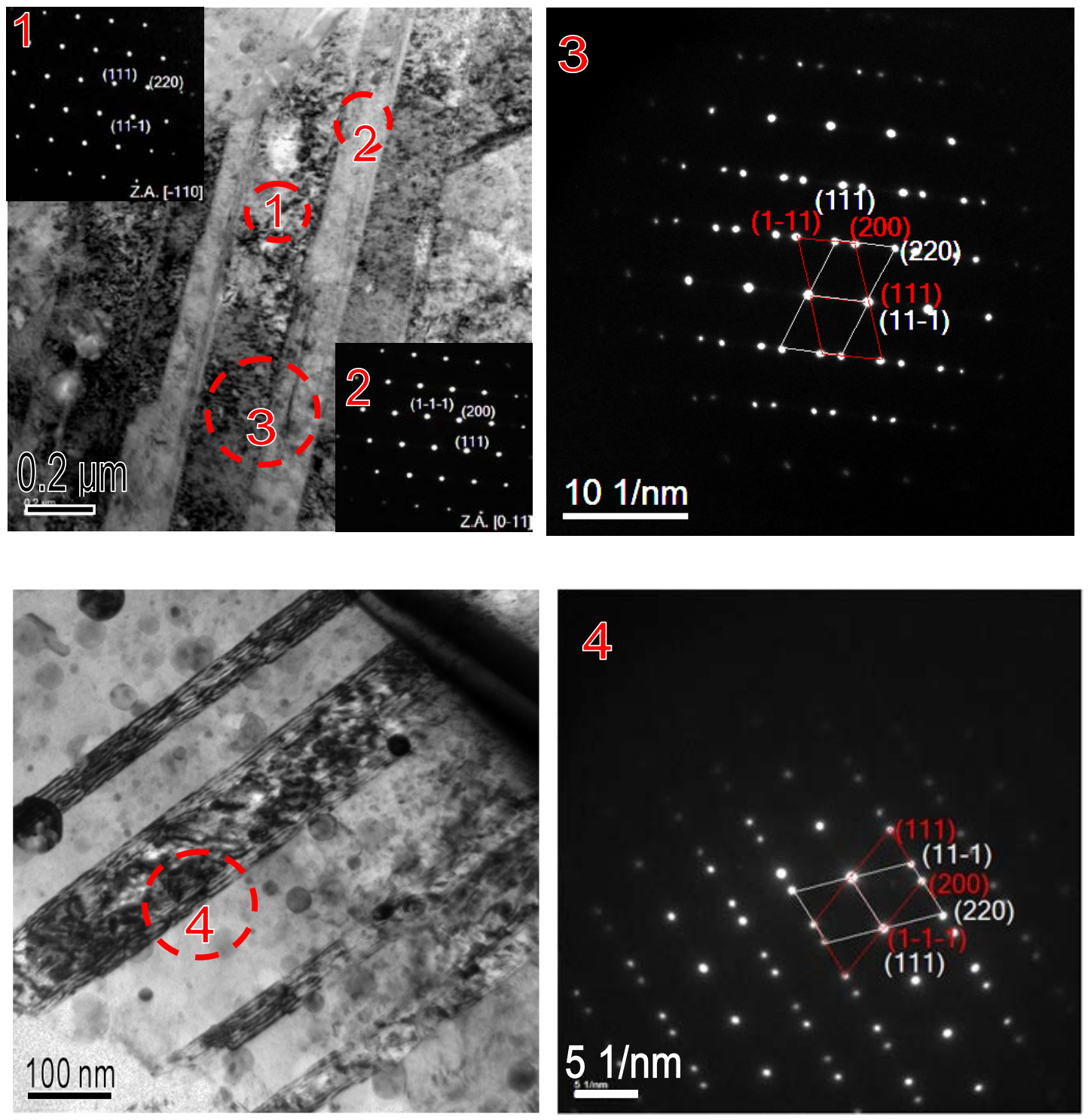

Fig. 10 TEM images and corresponding selected area diffraction (SAD) patterns of twins in the 5AlCo-ODS superalloy after tensile test at room temperature. 


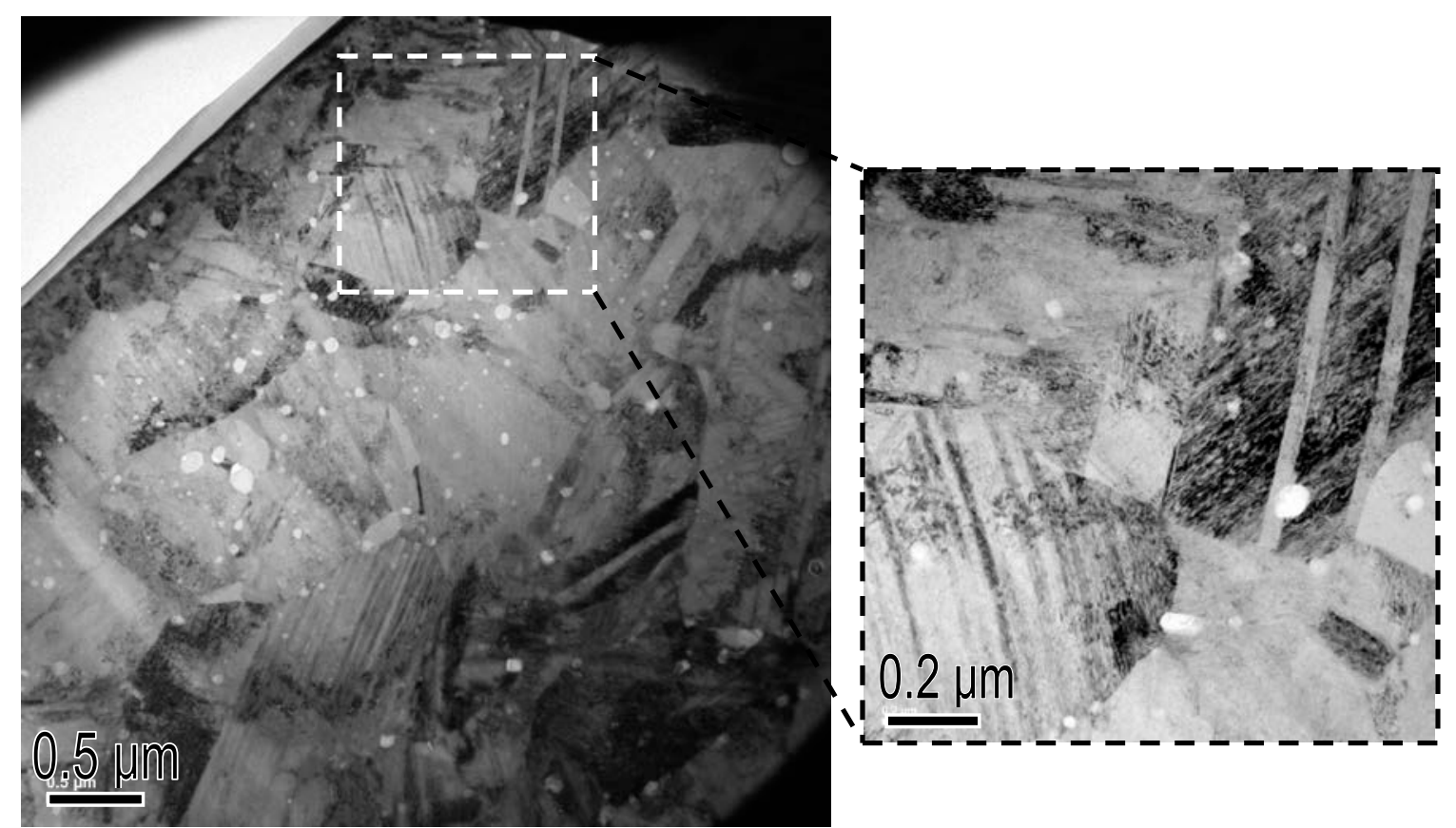

Fig. 11 TEM images of deformation twins in the 5AlCo alloy after tensile test at room temperature. 
(a)

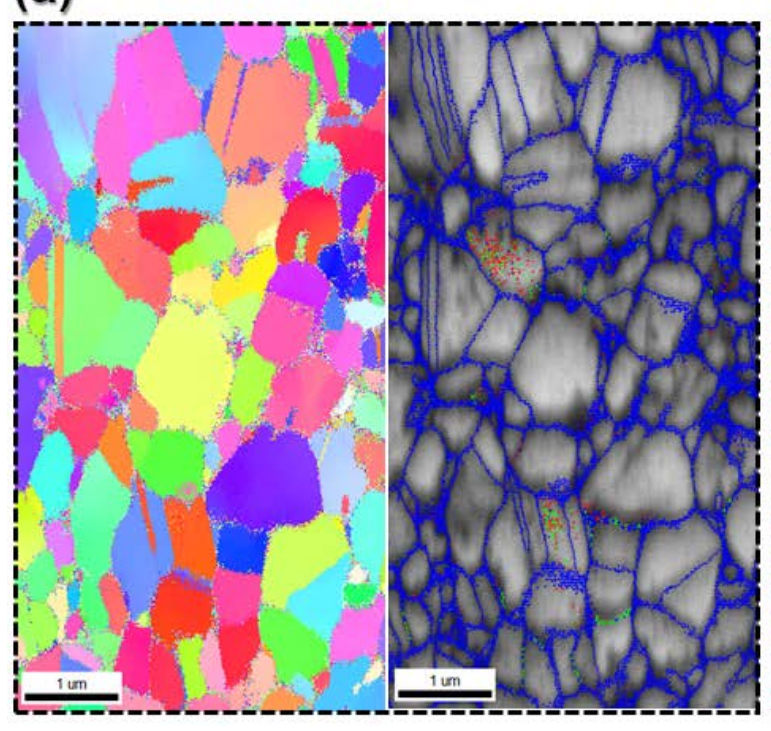

(b)

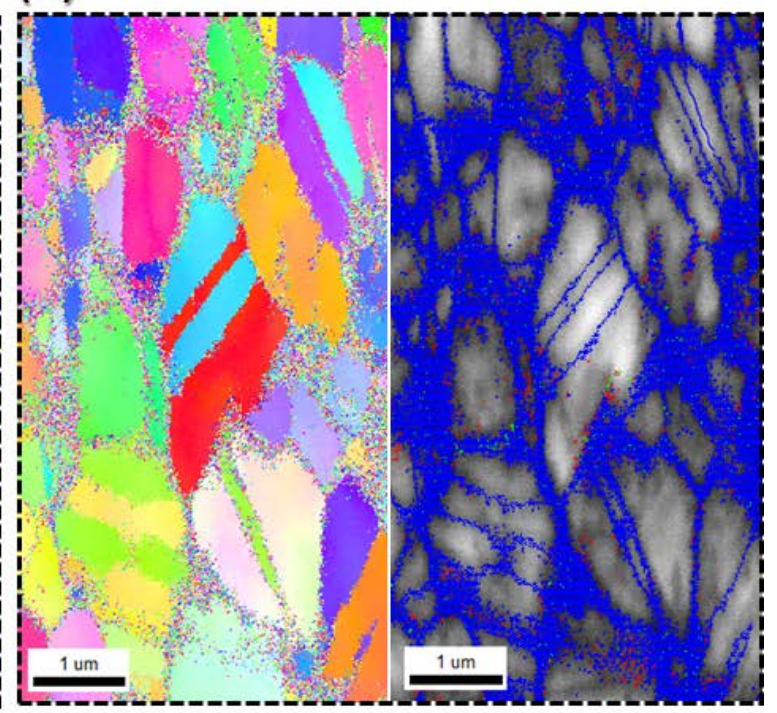

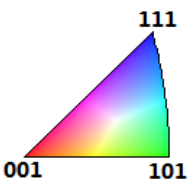

Fig. 12 OIM-IPF maps and corresponding IQ maps obtained from the tensile tested (room temperature) 5AlCo-ODS (a) and the 5AlCo samples (b). The grain boundaries and twin boundaries have been marked with blue lines by the TSL OIM Analysis 7.0 software. 


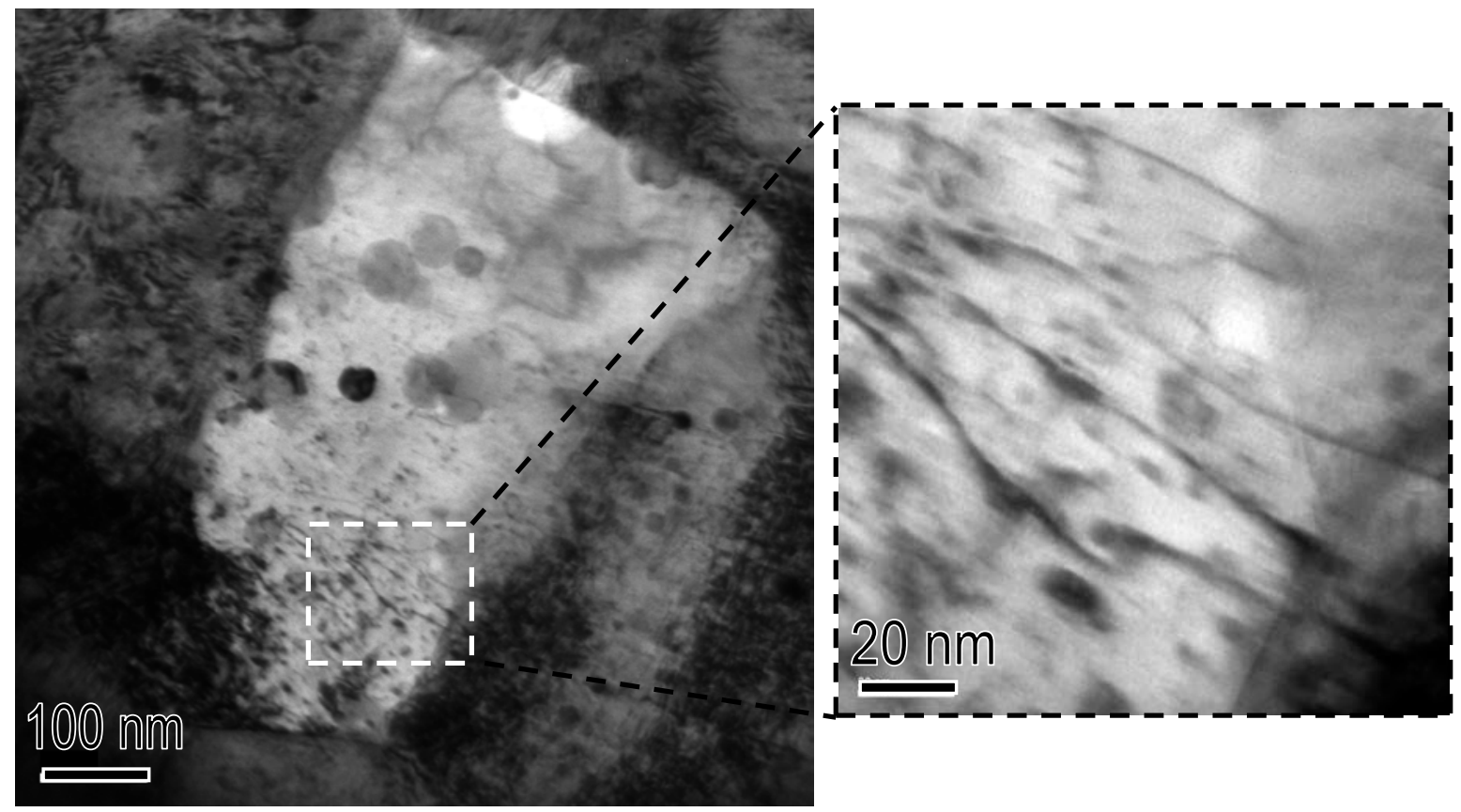

Fig. 13 TEM images of the 5AlCo-ODS superalloy after tensile test at room temperature. 


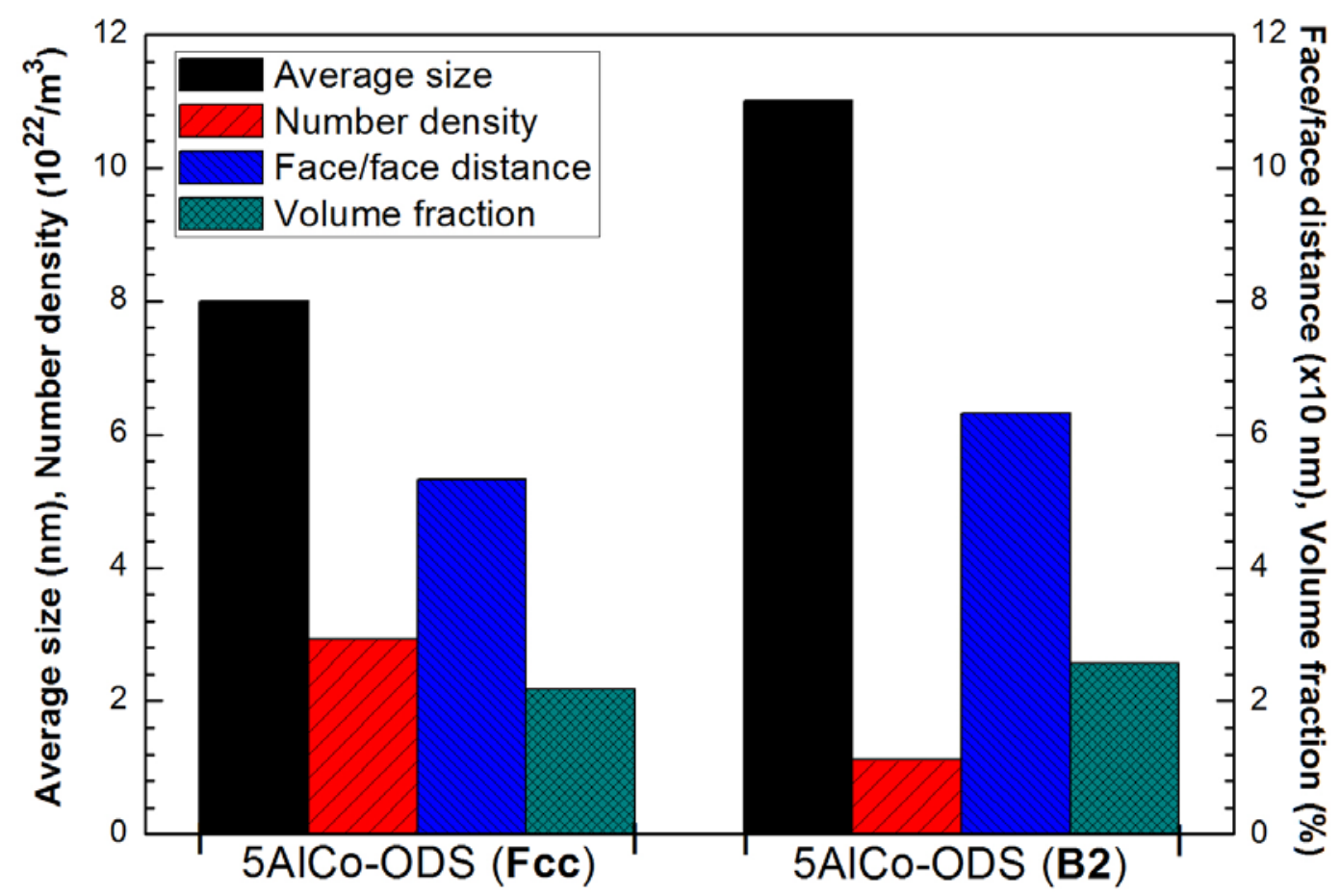

Fig. 14 Oxide particles distribution of the fcc and B2 phase on the 5AlCo-ODS superalloy. 


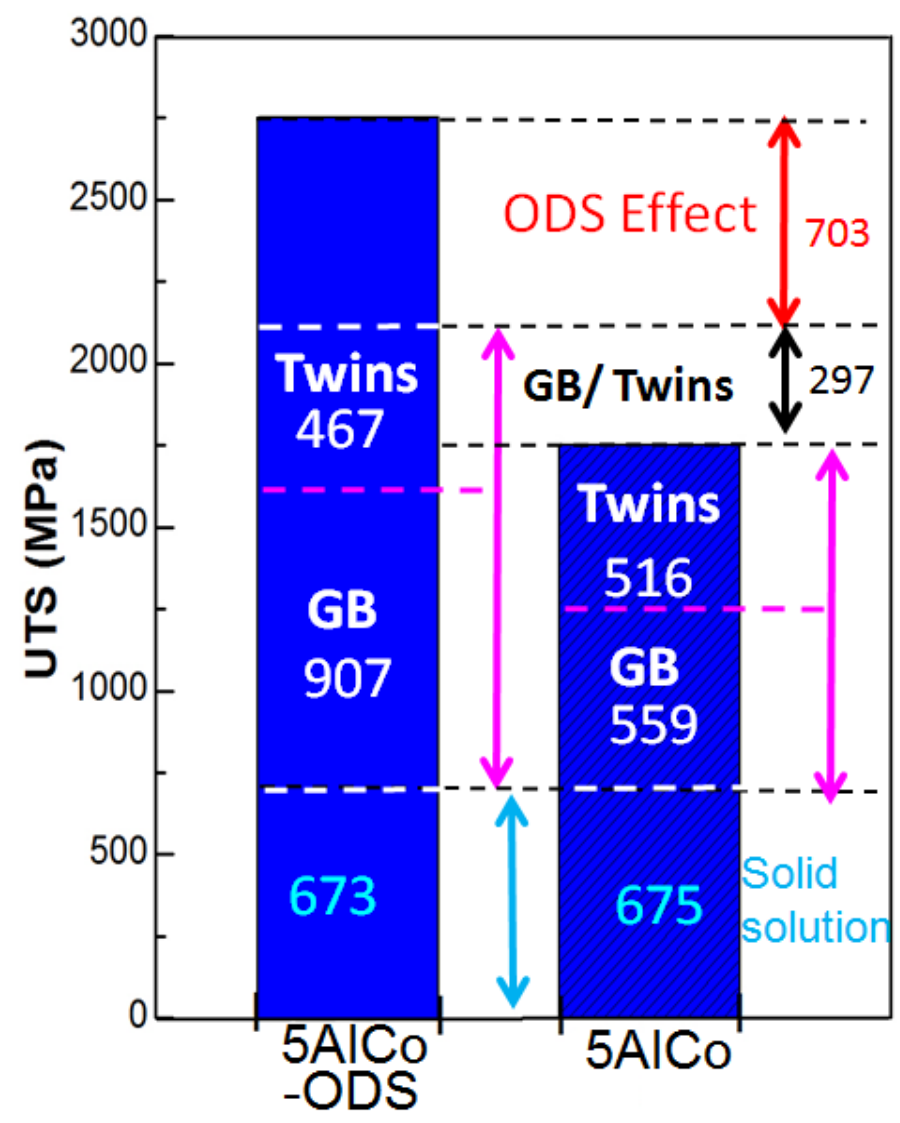

Fig. 15 Summarization for the components of the UTS at room temperature in the 5AlCo-ODS and the 5AlCo samples. 